\title{
Compartilhar as Américas: ressignificando a americanidade numa perspectiva relacional
}

\author{
Sharing the Americas: giving new meaning to Americanism in a relational perspective \\ Zilá Bernd \\ PPG-Letras/UFRGS. PPG-Memória Social/UNILASALLE
}

\begin{abstract}
Resumo: $\mathrm{O}$ artigo apresenta uma reflexão que tem origem na representação das Américas através de suas primeiras iconografias (Marten de Vos, Jan van der Straet, Philippe Galle) a partir das quais se instaurou o princípio da hierarquização das culturas em detrimento da cultura americana. Durante os quinhentos anos desde os "descobrimentos", as Américas iniciam o processo de desconstrução do sentimento de suposta dependência cultural europeia o qual constitui o dilema identitário das Américas. A estratégia mais bem sucedida revela-se pela busca de uma memória longa não mais na Europa, mas nas culturas autóctones. A tomada de consciência desse re-centramento aponta para práticas transculturais iniciadas ainda nos primeiros séculos depois da conquista quando os Guarani reproduzem os modelos do barroco europeu, introduzindo alterações relativas a sua identidade étnica. Com o modernismo brasileiro, ao lançar o Manifesto Antropófago, Oswald de Andrade está apontando para a necessidade de buscar nossa ancestralidade cultural entre os Tupinambá. Édouard Glissant, ao assinalar a supremacia do pensamento "de arquipélago" (autóctone) sobre o pensamento de sistema (racionalidade europeia) e ao preconizar a creoulização das culturas, está caminhando no mesmo sentido da busca de nossa memória de longa duração no coração da própria América. A noção de Americanidade, longe de propor a existência de uma grande narrativa homogênea, busca analisar os deslocamentos e a ressemantização de mitos através das três Américas e o trabalho de reapropriação que caracteriza as culturas americanas para além das estreitas noções de nacionalidade. Pensar hoje a Americanidade como construto heterogêneo implica deixar de lado o binarismo do tipo civilização/barbárie; centro/periferia, em favor da inclusão do Diverso e do terceiro excluído. $\mathrm{Na}$ esteira de trabalhos recentes de Patrick Imbert, aposta-se na implosão do pensamento polarizado, nas trocas transnacionais e na disposição para o relacional e para os encontros transculturais que favorecerão a constituição de redes de compartilhamento entre as Américas. Palavras-chave: Compartilhar; Americanidade; Reapropriação; Relações transversais; Perspectiva relacional
\end{abstract}

\begin{abstract}
This presentation is a reflexion originating in the representation of the Americas in its first iconographies (Marten de Vos, Jan van der Straet, Philippe Galle) from which a cultural hierarchical principle installed itself in detriment of the American culture. For the last five hundred years the Americas start the process of deconstructing this feeling of supposed cultural dependence. The most successful strategy has been revealing itself in the search for a long memory, not in Europe any longer, but in the native cultures. This conscious awakening to recenter points to transcultural practices initiated in the first centuries after the conquest when the Guarani deconstruct the models from the European baroque, proposed by the Jesuits. Brazilian modernism, as launched in Oswald de Andrade's Anthropophagic Manifest (1929), is pointing at the necessity of finding our cultural ancestrality among the Tupinambá's anthropophagic practices. Édouard Glissant, as he acknowledged the "archipelago" supremacy of thinking (pensée archipélique or native) over the system thinking (pensée de système or European rationality) and proposed the creolization of cultures, is walking in the same direction of the search for our long duration memory in the heart of America itself. The notion of Americaness, far from proposing the existence of a large homogenous narrative in the Americas, tries to analyze cultural mobilities, resemantization of myths throughout the three Americas and the process of reappropriation characteristic of American cultures beyond narrow notions of nationality. Today, to think Americaness as a heterogeneous construct, implies leaving aside binaries as civilization/ barbarism; center/periphery, in favor of including transversal relations. In the path of recent works, as Patrick Imbert's, we bet on the implosion of polarized thinking, on the transnational exchanges and in the natural disposition to the relational that will lead toward the formation of networks to share experiences in the Americas.
\end{abstract}

Keywords: Share; Americaness; Reapropriation; Transversal relations; Relational perspectives 


\section{[...] uma memória sem esperança} é contra-produtiva

e uma esperança sem memória não passa de ilusão.

(Patrick Imbert, 2015)

\section{Visões da América}

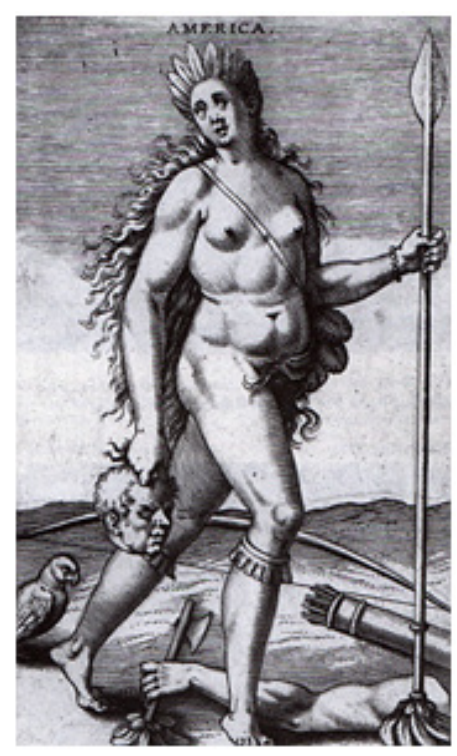

America - Philipe Galle, séc XVI

(Philippe Galle. 1579-1600

- Alegoria da América

<http://iberoamericasocial.com/

de-monstruo-alegoria-deamerica-las-amazonas/>)

A iconografia representando alegoricamente as Américas como uma mulher desnuda e selvagem é sobejamente conhecida de todos nós. Retorno a essas imagens para lembrar que pintores como Marten de Vos, Jan van der Straet e Philipe (ou Philips) Galle representam, de um lado, a Europa, como uma mulher ricamente vestida, enquanto a América é representada pela falta: de vestes, de ornamentos e emblemas que remetem à sabedoria e ao poder, além do cenário em que se encontram. Enquanto a Europa está em um jardim cultivado (uvas, flores) e rodeada de animais domesticados, a América é circundada por terras incultas e animais selvagens, incluindo cenas de canibalismo. Logo, desde as primeiras representações, instaurou-se o princípio da hierarquização das culturas em detrimento da cultura americana, caracterizada pela falta (sem vestes, sem lei, sem fé e ameaçadora, associada a práticas bárbaras como o canibalismo).

Temos que atentar, contudo, para o fato de que a nudez era a grande dominante da pintura renascentista, época em que tais imagens foram criadas, podendo também ser a representação de inocência e de erotismo inspirada por uma natureza paradisíaca, além do fato incontornável de muitas tribos americanas andarem desnudas. É preciso ainda lembrar que a maioria dos pintores nunca esteve no Novo Mundo, produzindo suas obras com base em relatos de viagem sobretudo nos de André Thévet, Hans Staden e Américo Vespúcio ${ }^{1}$.

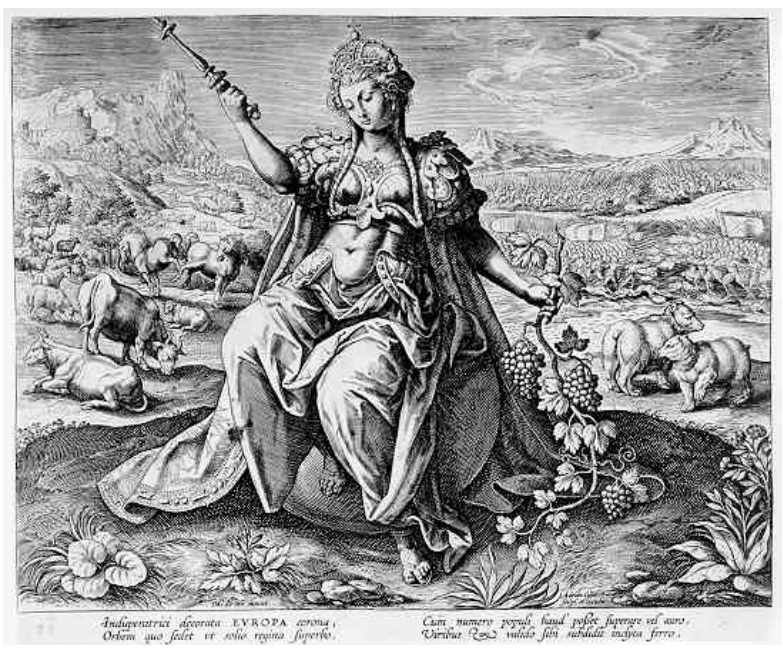

Europa, Marten de Vos - séc XVI

(Marten de Vos, Europa <http://commons.wikimedia.org/ wiki/File:Marten_de_Vos_Adriaen_Collaert_Europa.jpg >)

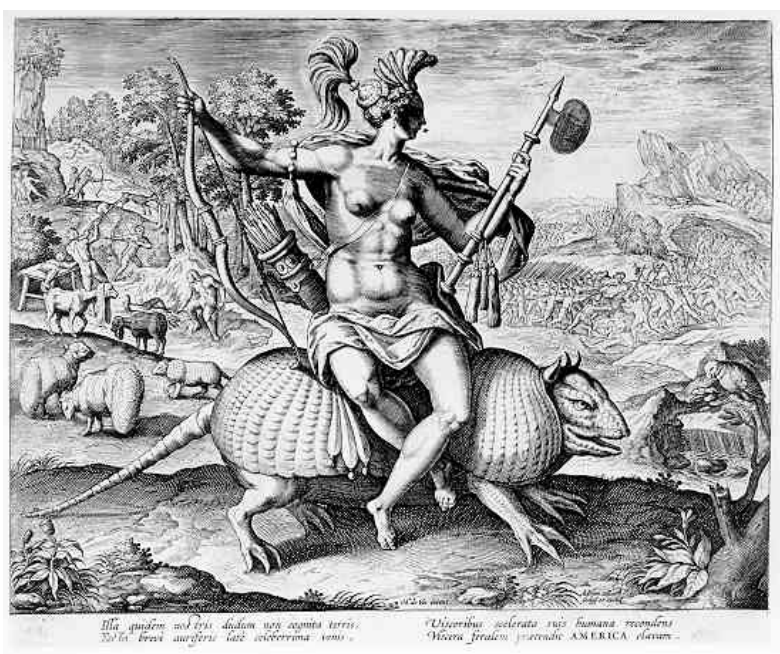

América, Marten de Vos, séc. XVI

(Marten de Vos, América <http://commons.wikimedia.org/ wiki/File:Marten_de_Vos_Adriaen_Collaert_America.jpg >)

Há portanto um caráter ambivalente nessas visões da América que, ao mesmo tempo, assombram e deslumbram os europeus que, seja através de relatos de viagem dos conquistadores, seja através da iconografia (prosopografia), produzirão imagens marcadas pelo exotismo, visão superficial de uma América ainda desconhecida ou conhecida apenas em sua faixa litorânea. Será preciso penetrar os "interiores do Novo Mundo" (les intérieurs du Nouveau Monde) para desconstruir essa visão primeira estereotipada e superficial que associava as Américas a primitivismo, natureza selvagem, grandes espaços, anti-intelectualismo e sobretudo à "experiência de uma privação e à angústia do vazio"2, para citar expressões do teórico quebequense Pierre Nepveu.

\footnotetext{
1 A. Thévet (1516-1590); H. Staden (1525-1579); A. Vespúcio (1454-1512).

2 Cf Pierre Nepveu, 1998, avant propos, p. 7-11.
} 
Desde os primeiros contatos, desenha-se, pois, uma representação mistificada das Américas que se inscreverá no discurso social e na memória coletiva de várias gerações, pois foi construída a partir de ideias forjadas e traduzida em imagens preconceituosas. Nesse sentido, toda a história da formação das literaturas nas Américas será uma história de reapropriação, de tentativas de assumir as rédeas da narrativa de fundação que será, ao mesmo tempo, uma narrativa de destruição dos estereótipos e clichês que moldaram o perfil americano revelado ao mundo.

\section{Recentramento e primeiras práticas transculturais}

Durante os quinhentos anos desde o "descobrimento" da América, temos nos empenhado em desconstruir esse sentimento de inferioridade, de suposta dependência cultural que nos faz olhar para o longe (Europa) em busca do tertium comparationis. A estratégia mais bem sucedida, para reverter tal situação, vem se revelando ser a busca de uma memória longa não mais na Europa, mas nas culturas autóctones. A tomada de consciência desse re-centramento aponta para práticas transculturais iniciadas ainda nos primeiros séculos depois da conquista, quando os Guarani reproduzem os modelos do barroco europeu alterando a coloração da pele, o formato dos olhos e colocando adereços indígenas nas esculturas que deveriam repetir simplesmente os modelos europeus.

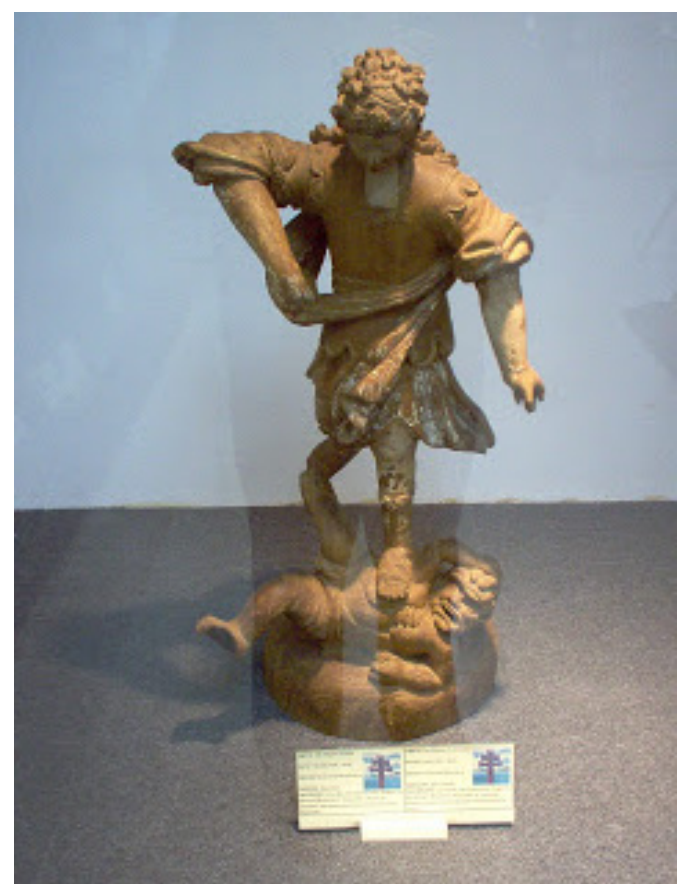

Arte Missioneira

(Imagem de São Miguel Arcanjo, séc. XVII <http://elmissioneiro.blogspot.com.br/>
As esculturas missioneiras falam por si só: entre 1710 e 1735, os Sete Povos das Missões, situados em territórios hoje ocupados por Brasil, Uruguai, Argentina e Paraguai, conheceram seu apogeu, manifesto através da arquitetura, da música e da escultura. Os jesuítas ofereciam aos índios o modelo do barroco europeu que foi paulatinamente sabotado pelos autóctones que nele introduziam elementos de sua própria realidade, criando os primeiros exemplares de uma arte compósita e transcultural. Nessa imagem de São Miguel Arcanjo nota-se a substituição do dragão - tradicional no modelo europeu - pela imagem do bandeirante, representando o mal, ou seja, a ameaça de escravização para os autóctones. Embora o modelo proceda de fontes tradicionais, "a mão indígena quebrou o bloqueio estético imposto pelos padrões importados, na figura do rosto (São Miguel apresenta traços característicos da etnia guarani) e na substituição do dragão pelo predador" (TREVISAN, s/d).

Alejo Carpentier nos ajuda a vislumbrar, em Los pasos perdidos (1953), a ocorrência do mesmo fenômeno em uma capela do México em cujo frontispício está esculpido um anjo (modelo do barroco europeu) tocando maracas, em um evidente embricamento da arte sacra europeia (o anjo) associada à tradição popular profana das Américas (as maracas). Com esses exemplos tirados das artes plásticas, evidencia-se o fenômeno da hibridação de materiais e da subversão dos modelos ritualizados que conformaram a arte do Novo Mundo desde seus primórdios. Nesse sentido, não têm fundamento as teorias que defendiam a tese da dependência cultural latinoamericana. A subversão dos modelos e a introdução da "impureza" americana, presente desde os primeiros momentos de nossa formação cultural, evidenciam a tendência da arte americana de constituir-se no entrelugar (in-between), para utilizarmos a expressão de Silvia Spitta.

Exemplos como esses marcam o início do que hoje chamamos de americanidade que corresponde a voltar o olhar para o que está perto (Américas) e que passará a nutrir a imaginação dos artistas, sendo fonte alternativa de inspiração (que era buscada, na grande maioria dos casos, do outro lado do Atlântico, sobretudo na Europa).

\section{Antropofagia cultural e crioulização}

No âmbito do modernismo brasileiro (1922), ao lançar o Manifesto Antropófago, em 1928, Oswald de Andrade apontava para a necessidade de buscarmos nossa ancestralidade cultural entre os Tupinambá. Édouard Glissant, ao assinalar a supremacia do pensamento "de arquipélago" (autóctone) sobre o pensamento de sistema (racionalidade europeia) e ao preconizar a crioulização (créolisation) das culturas, está caminhando no mesmo 
sentido da busca de nossa memória de longa duração no coração da própria América.

Ao se identificar com a antropofagia como prática dos Tupinambá à época da chegada dos descobridores, o brasileiro Oswald de Andrade está fazendo uma volta a práticas anteriores à presença dos europeus em solo americano. O Manifesto Antropófago preconiza que a formação cultural nas Américas deveria inspirar-se na prática antropofágica que previa a devoração apenas dos inimigos corajosos para, através do processo digestivo, absorver-lhes as virtudes. Logo não se praticava a antropofagia no Brasil apenas para matar a fome, mas como ritual o qual deve ser imitado no sentido de que possamos absorver todas as culturas que admiramos (europeia, indígena, africana) como um processo consciente e seletivo que passa pela digestão. $\mathrm{O}$ que importa reter é transformado em energia vital e o que não interessa é eliminado como no processo digestivo. Tal proposta do início do século XX permanece incrivelmente atual, pois implica a ultrapassagem de uma visão binária (Europa vs América) e redutora, já que se fundamenta em um processo complexo de interações e de negociações identitárias. A Antropofagia cultural constitui-se em uma proposta de construção da identidade cultural brasileira alicerçada na heterogeneidade, nas passagens transculturais entre as diversas heranças culturais absorvidas e na aceitação do caráter necessariamente híbrido da cultura americana. "Tupi or not Tupi, that is the question" (ANDRADE [1928], 1995, p. 47).

Na região multiétnica e pluricultural do Caribe, a tendência ao essencialismo que caracterizou a Negritude será substituída pela crioulização definida como sendo "um agregado interacional (de influências recíprocas) ou transacional (concessões recíprocas) de elementos culturais caribenhos, europeus, africanos, asiáticos, etc. que a história reuniu em um mesmo solo"3 (BERNABÉ et al., 1989, p. 26). É portanto fruto de um turbilhão (maelstrom) de significados em um só significante, constituindo uma especificidade aberta. Os autores do Éloge de la créolité (Jean Bernabé, Patrick Chamoiseau e Raphael Confiant) distinguem americanidade, antilhanidade e crioulidade, conceitos que poderiam, no limite, recobrir as mesmas realidades. Os processos de americanização e o sentimento de americanidade dela decorrente servem para descrever as diferentes etapas de negociação e de adaptação das populações de diferentes origens étnicas ao Novo Mundo.

Na esteira do Éloge de la créolité, Édouard Glissant teoriza sobre Diversidade e Relação em Poétique de la relation (1990), preconizando os encontros transculturais na região caribenha em uma perspectiva relacional, que destaca as constantes transformações que se operam entre umas e outras. Incorporando a situação de pluralidade cultural da região caribenha, o autor postula os entendimentos transculturais como possibilidade de incremento das relações culturais inter e trans-americanas. Tais relações não implicam perda nem cópia, pois originam algo novo no âmbito das mobilidades interhemisféricas (cf. BENESSAIEH, 2010, p. 235).

\section{Americanidade e mobilidades transculturais}

A noção de Americanidade, longe de propor a existência de uma grande narrativa homogênea, busca analisar os deslocamentos e a ressemantização de mitos através das três Américas e o trabalho de reapropriação que caracteriza as culturas americanas para além das estreitas noções de nacionalidade. Pensar hoje a Americanidade como construto heterogêneo implica deixar de lado o binarismo do tipo civilização/barbárie; centro/periferia; pureza/mestiçagem, que caracterizou boa parte dos estudos americanistas até praticamente o final do séc. XX - e que não nos libertava da fixação com as culturas europeias -, em favor da inclusão do Diverso e do terceiro excluído.

Os países da América Latina estiveram durante o século XIX tão empenhados em definir suas identidades nacionais que esqueceram de demarcar sua pertença à América, deixando de auto-denominar-se americanos. Talvez isso tenha acontecido porque os Estados Unidos tomaram para si a apelação autovalorizante de "americanos", incluindo nessa apelação tão somente os estadunidenses. Falar hoje em americanidade é, de certa forma, uma tomada de consciência de nossa pertença à América, correspondendo a um desejo de nos autoproclamarmos americanos apesar da extraordinária heterogeneidade que caracteriza nosso continente. Bell Galé Chavigny e Gari Laguardia afirmam, em Reinventing the Americas, Comparative Studies of Literature of the United States and Spanish Americas (Cambridge University Press, 1986), que "the reinvention of the Americas must begin with exposure of the rhetorical incoherence we commit each time we designate the United States by the sign America, a name that belongs by rights to the hemisphere..." (apud LAROCHE, 1992, p. 195$)^{4}$.

A Americaniade na América Latina começa com os processos de transculturação e de hibridação, com o valor agregado da imprevisibilidade. No que diz respeito à América Latina, Gérard Bouchard fala de americanidade

\footnotetext{
3 "La Créolité est um agrégat interactionnel ou transactionnel des éléments culturels caraïbes, européens, africains, asiatiques, et levantins, que le joug de l'Histoire a réunit sur le même sol.” (1989, p. 26).

4 "a reinvenção das Américas deve começar expondo a incoerência radical que cometemos cada vez que designamos os Estados Unidos pelo signo América, nome que pertence de direito ao hemisfério."
} 
inacabada. Acreditamos que a incompletude possa ser uma vantagem, pois os processos de identificação estão em permanente devir: o que interessa não é propriamente a conclusão do processo, mas o fato de que as trocas, as interpenetrações e os processos de desierarquização continuem a realizar-se e que a ideia de uma americanidade compartilhada entre o Norte e o Sul possa criar as condições da Relação de que fala Glissant.

Talvez seja no âmbito do imaginário mítico americano que encontraremos os códigos de decifração e de reinvenção da americanidade. Será preciso, como observa Walter Mignolo, esperar a emergência de novos lugares de enunciação (loci of enunciation) para trazer à tona conhecimentos que foram considerados subalternos durante a colonização (MIGNOLO, 2000, p. 3-45). Redescobrir na oralidade, na sabedoria popular e na gnoseologia marginal (border gnosis) novas formas de habitar as Américas e de definir nossa pertença a elas pode ser a via de acesso à americanidade como lugar de resistência e de recuperação da diferença colonial (colonial diference).

\section{Dilemas do diálogo transcultural}

$\mathrm{Na}$ esteira de trabalhos recentes de Patrick Imbert, apostamos na implosão do pensamento polarizado, nas trocas transnacionais e na disposição para o relacional e para os encontros transculturais que favorecerão a constituição de redes de compartilhamento nas Américas.

Fala-se hoje com justeza no caráter inacabado das Américas; considera-se, contudo, que o mais importante e urgente é falar em Américas compartilhadas. Como refere Patrick Imbert em recente publicação:

Vê-se que as diversas culturas que se encontraram nas Américas podem contribuir para a constante invenção das Américas [...]. De fato, como lembra Cornel West (2009) ao se inspirar no pragmatismo de Charles Sanders Peirce (1982), as Américas continuam em suspenso. Elas são um continente que ainda deve ser completado, como lembra também Rivard em $L e$ siècle de Jeanne, quando compara a América a um canteiro de obras. O objetivo é conseguir inventar solidariedades novas e comunidades de interesses geradoras de produtividades sociais, econômicas, científicas e culturais para lutar contra a falta de humanidade enraizada na memória das coletividades imigrantes, minoritárias, autóctones e, na verdade, de todas as coletividades, sabendo que uma memória sem esperança é contra-produtiva e que a esperança sem memória não passa de uma ilusão. 5,6

Patrick Imbert, em seu último livro, Comparer le Canada et les Amériques; des racines aux réseaux transculturels (2014), fala de réseautage, na perspectiva de que a cultura deve favorecer o encontro dos indivíduos através do compartilhamento, "ela permite a troca e a gestão dos saberes em processos de globalização em rede (réseautage/network)" (2014, p. 238). O conceito de redes (como as redes neuronais, por exemplo) é tridimensional, sendo adequado para ser utilizado como metáfora do caráter tridimensional das relações literárias inter e transamericanas. Segundo o filósofo e teórico da informática, Pierre Lévy,

Les réseaux permettent de mettre en commun nos mémoires, nos compétences, nos imaginations, nos projets, nos idées, et de faire en sorte que toutes les différences, les singularités se relancent les unes les autres, entrent en complémentarité, en synergie. $(1998)^{7}$

Lévy chega até mesmo a falar na formação: (1) de "comunidades de saber" (communautés de savoir), questionando-se sobre a possibilidade dessas comunidades virem a fundir-se, em uma "consciência universal" (conscience universelle) ${ }^{8}$, e (2) de "inteligência das redes", citando Derrick Kerckhove que cunhou essa expressão, afirmando que o pensamento hoje não é mais hierarquizado, mas interativo.

Provavelmente nem a escolha da metáfora das "comunidades de saber" nem a das "redes de inteligência" serão soluções definitivas para os interessados nos dilemas americanos. Interessa, contudo, apontar para a necessidade hoje de uma reconfiguração já que na atualidade as taxionomias de "migrante" e "transnacional" deixam de contemplar toda uma gama de escritos que ultrapassam determinadas convenções e limites. Estudos sobre as Américas em perspectiva comparada, que buscam identificar pontos de convergência e observar as diferentes trajetórias dos mitos fundadores, que passarão a

\footnotetext{
IMBERT, Patrick. Comparer le Canada et le Brésil em fonction des paradigmes opératoires: de l'exclusion au transculturel. In: IMBERT, P.; BERND, Z. éds. Envisager les rencontres transculturelles BrésilCanada. Québec: Presses de l'Université Laval, 2015. (sous presse).

6 Dans ce contexte, on voit que les diverses cultures qui se sont rencontrées dans les Amériques peuvent contribuer à constamment inventer les Amériques, le Brésil et le Canadá em particulier. Em effet, comme le rappelle Cornel West s'inspirant Du pragmatisme de Charles Sanders Pierce, les Amériques restent encore em suspens. Elles sont um continent qui reste à compléter comme le rappelle aussi Yvon Rivard dans le Siècle de Jeanne (2005) lorsqu'il qualifie l'Amérique de chantier. Le but est de réussir á inventer des solidarités nouvelles et des communautés d'intérêts créatrices de productivité sociale, économique, scientifique et culturelle pour lutter contre le manque d'humanité dont les collectivités immigrantes, les collectivités minoritaires, les collectivités autochtones et, em fait, toutes les collectivités, gardent La mémoire, em sachant qu'une mémoire sans espoir est contre-productive et que l'espoir sans mémoire n'est qu'illusion. (IMBERT, 2015, sous presse).

7 As redes permitem relacionar nossas memórias, nossas competências, nossas imaginações, nossos projetos, nosssas ideias, e fazer de modo que todas as diferenças, as singularidades se relancem umas as outras, entrem em complementaridade, em sinergia.

$8<$ http://fr.wikipedia.org/wiki/Intelligence_collective_sur_Internet\# Internet.2C le r.C3.A9seau c.C3.A9r.C3.A $\overline{9}$ bral plan. $\bar{C} 3 . A \overline{9}$ taire>.
} 
constituir diferentes constelações em suas migrações pelas Américas, são relativamente recentes tendo dado origem a teses como americanidade, crioulização, transculturação, migrância (literaturas migrantes) e transnacionalidade (literaturas transnacionais). Esses conceitos emergem quando passamos a entender a precariedade e a insuficiência do conceito de literaturas nacionais para dar conta das mobilidades culturais que caracterizaram o continente americano. Mobilidades espaciais, temporais, migratórias, transacionais e nomadismos de toda espécie levaram à falência práticas limitadoras, que costumavam associar literatura e cultura, ao espaço nacional.

Tem sido de suma importância pensarmos as produções literárias das Américas em termos de passagens, movimentos transculturais com suas fertilizações recíprocas que deram origem a produtos culturais novos, que escapavam a classificações tradicionais como as baseadas no conceito de nação. Tais literaturas passaram a ser chamadas de migrantes (sobretudo no espaço francófono) e de transnacionais (principalmente no espaço anglófono), chamando a atenção para os deslocamentos, para a hibridação cultural e para o fato de se originarem em zonas de contato (contact zones, para retomarmos a expressão cunhada por Mary Louise Pratt). As literaturas americanas, oriundas da fricção de duas ou mais culturas, constituem fatos culturais novos que não pertencem mais apenas ao horizonte cultural do país de origem ou ao horizonte cultural do país de acolhida, engendrando paisagens culturais originais e desafiadoras.

As mobilidades culturais da modernidade tardia desafiam a levar nossa reflexão para além dos transnacionalismos (beyond transationalisms), propondo novas terminologias que possam abarcar as variáveis de um mundo globalizado. Pierre Ouellet, escritor e teórico do Quebec, e Kenneth White, ensaísta e poeta de origem escocesa, mas que vive entre Paris e Montreal, publicaram respectivamente: L'esprit migrateur (o espírito migrante), em 2005, e L'esprit nomade (1987) nos quais reivindicam para os escritores não migrantes e não-transnacionais, isto é, aqueles que nasceram e escreveram sempre em um mesmo território, a condição de migrantes intelectuais ou nômades espirituais, por terem a liberdade de escolher sua ancestralidade intelectual e de dialogar - sem sair de seus escritórios - com culturas as mais longínquas e as mais diversas.

Se todos nós somos migrantes nesse mundo globalizado e "googlelizado", os conceitos de "literaturas migrantes" e/ou "transnacionais" ficam esvaziados, perdem seu sentido. Por isso, proponho pensar para além dos transnacionalismos, pois quando falamos de transnacionalismos estamos ainda presos à ideia de nação, embora aparentemente estejamos rompendo com ela. Falar em redes de inteligência ou em comunidades de saber pode corresponder a uma mudança mais radical, pois nos permite imaginar a projeção de "famílias" ou "comunidades" de autores e/ou obras que compartilham um estoque memorial comum, ou seja, comunidades de autores cujas obras constituem formas semelhantes de organização e ordenação do imaginário coletivo americano.

Seria oportuno nesse momento mencionar o conceito de "comunidades de memória" (communautés de mémoire), proposto por Pierre Ouellet em obra de 2012 (Testaments. Le témoignage et le sacré). $\mathrm{O}$ autor considera que no contexto atual de constantes mobilidades culturais, mais importante do que falar de identidades nacionais ou mesmo transnacionais, é falar de "comunidades de memória", conceito que leva em conta, para além da memória dos povos fundadores, as culturas dos recémchegados a um determinado país, constituindo através de trocas (ex-changes) uma memória múltipla que o autor denomina "comunidade de memória".

\begin{abstract}
Não se trata de uma memória comum (ou coletiva) porque ela pertence a várias tradições, com diferentes histórias, desenvolvidas em diversos lugares, mas o fato de que pessoas de diferentes origens participem agora da sociedade quebequense, faz com que vivamos em uma comunidade de memórias ${ }^{9,10}$.
\end{abstract}

Falar nos dias de hoje sobre literaturas das Américas seria falar não de uma narrativa comum, d'un grand récit des Amériques, mas de diferentes comunidades de memória (Ouellet) ou de saber (Lévy) que adotam e compartilham diferentes memórias em um verdadeiro festim antropofágico...

Esperamos ter - se não resolvido a complexa questão das etiquetas e dos rótulos que envolve o comparatismo inter e trans-americano - ter, ao menos, apontado para a relatividade de sua importância. Se os conceitos ligados ao "trans": transnacional, transcultural, etc. fertilizaram nossas reflexões sobre o espaço cultural e literário americano e sobre os impactos trazidos pela "ocupação" dos "modelos" europeus, já é hora de pensarmos para além dos transnacionalismos. Seguindo os ensinamentos glissantianos sobre Diversidade e Relação, seria fertilizador refletirmos sobre as Américas em termos de redes interativas e não-hierárquicas sobre as quais fala Pierre Lévy em seus últimos livros, e sobre as

\footnotetext{
9 Entrevista realizada com Pierre Ouellet por Ana M. Lisboa de Mello, Zilá Bernd e Marie Hélène Parret Passos, publicada na revista Letras de Hoje, PUCRS, v. 50, n.2, abr.-jun., 2015, p. 229-240

${ }^{10}$ Ce n'est pas une mémoire commune (ou collective) parce qu'elle appartient à plusieurs traditions, plusieurs histoires différentes, plusieurs lieux où elle s'est développée, mais le fait que tous ces gens [immigrants de différentes origines], maintenant, participent de la société québécoise, ou canadienne française, fait en sorte que l'on vit dans la communauté de mémoires.
} 
generosas propostas de Pierre Ouellet, com seu conceito de "comunidades de memória", e de Patrick Imbert, que nos fala de (com)partilhar saberes e experiências no vasto espaço das Américas. Compartilhar as Américas para ressignificar a americanidade, na perspectiva relacional: eis um belo desafio para os anos que virão!

\section{Referências}

ANDRADE, Oswald. Manifesto Antropófago. In: ANDRADE, O. Obras completas: A utopia: a utopia antropofágica. 2. ed. São Paulo: Globo, 1995. p. 47-52.

BENESSAIEH, Afef (Dir.). Transcultural Américas/Amériques transculturelles. Ottawa: Presses de l'Université d'Ottawa, 2010.

BERNABÉ, Jean et al. Éloge de la créolité. Paris: Galimard, 1989.

BERND, Zilá (Org.). Americanidade e transferências culturais. Porto Alegre: Movimento, 2003.

BERND, Z. Américanité et mobilités transculturelles. Québec: Presses de l'Université Laval, 2009. Collection Americana.

BERND, Z.; LOPES, C. G. (Orgs.). Identidades e estéticas compósitas. Porto Alegre: UFRGS; Canoas: Unilasalle, 1999.

BISSOONDATH, Neil. Selling Illusions; the Cult of Multiculturalism in Canada. Toronto: Penguin Books, 1994.

CHAVIGNY ET LAGUARDIA (1986). Apud LAROCHE, Maximilien. Américanité et Amériques. In: PETERSON, M.; BERND, Z. (Éds.). Confluences littéraires Brésil-Québec. Montréal: Balzac, 1992. p. 189-202.

IMBERT, Patrick. Comparer le Canadá et les Amériques; des racines aux réseaux transculturels. Québec: PUL, 2014. Collection Américana.

IMBERT, Patrick. Les Amériques transculturelles; les stéréopyoes du jeu à somme nulle. Québec: PUL, 2013. Collection Ameriana.

IMBERT, Patrick (Ed.). Multiculturalism in the Americas; Canada and the Americas. Ottawa: Université d'Ottawa. Chaire de recherche de l'UOttawa: "Canada: enjeux sociaux et culturels dans une société de savoir”. 2011.
IMBERT, Patrick. Trajectoires culturelles transaméricaines; médias, publicité, littérature et mondialisation. Ottawa: Les Presses de l'Univiersité d'Ottawa, 2004.

LÉVY, Pierre. <http:/ecrans.liberation.fr/ecrans/1998/01/16/ pour-pierre-levy-philosophe-la-cyberculture-incarne-certainsideaux-revolutionnaires-xxie-siecle-des_225223>. Acesso em: 10 maio 2015.

LESEMAN, F.; CÔTÉ, J.-F. (Éds.). La construction des Amériques aujourd'hui; regards croisés transnationaux et transdisciplinaires. Québec: Presses de l'Université du Québec, 2009.

MIGNOLO, Walter. Local Histories/Global Designs; Colonialty, Subaltern knowledges, and Border Thinking. Princeton: Princeton University Press, 2000.

NEPVEU, Pierre. Les intérieurs du Nouveau Monde. Montréal: Boréal, 1998.

PRATT, Mary Louise. Os olhos do Império: relatos de viagem e transculturação. Trad.: Jésio Hernani Bonfim Gutierrrez. Florianópolis: EDUSP, 1999.

OUELLET, Pierre. L'esprit migrateur; essai sur le non-sens commun. Montréal:VLB éditeur, 2005.

OUELLET, Pierre. Testaments. Le témoignage et le sacré. Montréal: Líber, 2012.

OUELLET, Pierre. Entrevista concedida a Z. Bernd, Ana Maria L. de Mello e Marie-Hélène P. Passos para a revista Letras de Hoje, PUCRS, v. 50, n. 2, abr.-jun. 2015.

REDES (conceito de): Conceito de redes: $<$ http://www.larousse. fr/encyclopedie/divers/Internet/125060>.

SPITTA, Silvia. Between two watters; narratives of transculturation in Latin America. Huston: Rice University Press, 1995.

TREVISAN, Armindo. Os sete povos das Missões. Porto Alegre: Painel Editora/Rede Brasil Sul, [s/d.]. Ilustrada.

WHITE, Kenneth. L'esprit nomade. Paris: Grasset, 1987.

ZIEBELL, Zinka. Terra de canibais. Porto Alegre: Editora da Universidade (UFRGS), 2002.

Recebido: 03 de julho de 2015

Aprovado: 10 de setembro de 2015

Contato: zilabster@gmail.com 